\title{
The obesity paradox in patients undergoing transcatheter aortic valve implantation: is there any effect of body mass index on survival?
}

\author{
Tomasz A. Tokarek ${ }^{1}$, Artur Dziewierz ${ }^{1,2}$, Danuta Sorysz ${ }^{1}$, Maciej Bagieński ${ }^{1}$, \\ Łukasz Rzeszutko', Agata Krawczyk-Ożóg ${ }^{1}$, Dariusz Dudek ${ }^{1,2,3}$, Paweł Kleczyński ${ }^{1,2}$ \\ $12^{\text {nd }}$ Department of Cardiology and Cardiovascular Interventions, University Hospital, Krakow, Poland \\ ${ }^{2} 2^{\text {nd }}$ Department of Cardiology, Institute of Cardiology, Jagiellonian University Medical College, Krakow, Poland \\ ${ }^{3}$ Department of Interventional Cardiology, Institute of Cardiology, Jagiellonian University Medical College, Krakow, Poland
}

\begin{abstract}
Background: Conflicting results have been presented regarding the influence of body mass index (BMI) on outcomes among patients undergoing transcatheter aortic valve implantation (TAVI).

Aims: To investigate the impact of BMI on clinical outcomes after TAVI.

Methods: A total of 148 consecutive patients were categorised using baseline BMI according to the World Health Organization criteria. Baseline patient characteristics, frailty, and procedural and clinical outcomes including 30-day and 12-month all-cause mortality were compared between the BMI categories. Patients were followed up for a median of 460.0 (182.0-1042.0) days.

Results: Obesity was diagnosed in 37 (25.2\%) patients, 73 (49.7\%) patients were overweight, and 37 (25.2\%) had normal weight. Prevalence of lower frailty as assessed by five-metre walk test was confirmed in obese patients as compared to other groups. A trend towards a lower rate of in-hospital bleeding complications (18 [48.6\%] vs. 21 [28.8\%] vs. 9 [24.3\%] in normal-weight, overweight, and obese patients, respectively; $p=0.06)$ and less frequent blood transfusions (18 [48.6\%] vs. $17[23.3 \%)$ vs. $8[21.6 \%] ; p=0.016)$ was observed in overweight and obese groups. The rate of grade 3 acute kidney injury was lowest in the overweight group (4 [10.8\%] vs. $1[1.4 \%]$ vs. $3[8.1 \%] ; p=0.05)$. There was no difference between the groups in terms of 30-day all-cause mortality $(p=0.15)$. However, 12-month all-cause mortality was lowest in obese patients (12 [32.4\%] vs. 10 [13.7\%] vs. 2 [5.4\%]; $p=0.004)$. Increase in BMI was independently associated with lower all-cause mortality (hazard ratio [95\% confidence interval] per $1 \mathrm{~kg} / \mathrm{m}^{2}$ increase: 0.91 [0.845-0.98]; $p=0.018$ ).

Conclusions: Increased BMI was independently associated with survival benefit after TAVI.
\end{abstract}

Key words: aortic valve disease, frailty, obesity paradox, registry, transcatheter aortic valve replacement

Kardiol Pol 2019; 77, 2: 190-197

\section{INTRODUCTION}

Obesity is as a major modifiable risk factor for an increased risk of cardiovascular morbidity and mortality [1]. Despite their detrimental effects on general health status, overweight and obesity were linked with a protective effect in a wide range of cardiovascular interventions [2-5]. This discrepancy was also reported in patients with severe aortic stenosis (AS) undergoing transcatheter aortic valve implantation (TAVI) [3, 6-12]. However, some studies reported no effect of body mass index
(BMI) on outcomes in patients undergoing TAVI [13, 14]. The validated mechanisms of this obesity paradox are elusive. However, several possible explanations were postulated, including the paracrine effect of the adipose tissue [15]. Importantly, the number of obese patients with severe AS scheduled for TAVI is substantial and will continually increase as a result of the aging of the population. Thus, we sought to evaluate the impact of BMI on clinical outcomes after TAVI and to determine the validity of the obesity paradox in this group of patients.

\section{Address for correspondence:}

Paweł Kleczyński, MD, PhD, $2^{\text {nd }}$ Department of Cardiology, Institute of Cardiology, Jagiellonian University Medical College, ul. Kopernika 17, 31-501 Kraków, Poland, tel: +48 1242471 81, fax: +48 1242471 84, e-mail: kleczu@interia.pl

Received: 16.09.2018 Accepted: 18.12.2018 Available as AoP: 19.12.2018

Kardiologia Polska Copyright (C) Polish Cardiac Society 2019 


\section{METHODS}

Data on 148 consecutive patients with symptomatic severe AS scheduled for TAVI, who were considered inoperable or too high-risk for a conventional surgical aortic valve replacement, were collected between the years 2008 and 2015 [10]. The height and weight of all the patients were measured by medical staff on admission. The BMI was calculated as the body mass in kilograms divided by the square of the height in metres $\left(\mathrm{kg} / \mathrm{m}^{2}\right)$. Patients were stratified according to BMI categories adopted from the World Health Organization and National Institutes of Health guidelines and classified as underweight $\left(\leq 18.4 \mathrm{~kg} / \mathrm{m}^{2}\right)$, normal-weight $\left(18.5-24.9 \mathrm{~kg} / \mathrm{m}^{2}\right)$, overweight $\left(25.0-29.9 \mathrm{~kg} / \mathrm{m}^{2}\right)$, or obese $\left(\geq 30 \mathrm{~kg} / \mathrm{m}^{2}\right)$ [16]. Frailty evaluation was described previously [10]. The assessment of adverse events was in accordance with the Valve Academic Research Consortium (VARC)-2 definitions [17]. A local institutional ethical board approved the research protocol, and written, informed consent was obtained from all participants. Patient anonymity was preserved. The study was conducted according to the ethical guidelines of the 1975 Declaration of Helsinki with later amendments.

\section{Statistical analysis}

Categorical variables were expressed as number of patients (percentage) and compared using the $\chi^{2}$ or Fisher exact test as appropriate. Median and interquartile range (IQR) were used for continuous variables, which were compared using the Kruskal-Wallis test. Differences in outcomes were presented as age-/sex-adjusted odds ratios (ORs) with $95 \%$ confidence intervals (Cls). Survival was estimated using the Kaplan-Meier method according to BMI categories. Furthermore, a multivariate Cox proportional hazards model was constructed to identify independent predictors of all-cause mortality during maximal follow-up. All baseline variables were considered (age, sex, BMI, estimated glomerular filtration rate, arterial hypertension, diabetes mellitus, atrial fibrillation, previous myocardial infarction, previous percutaneous coronary intervention, previous coronary artery bypass grafting, chronic obstructive pulmonary disease, incomplete revascularisation, previous stroke/transient ischaemic attack, pacemaker implantation, logistic EuroSCORE I, the Society of Thoracic Surgeons [STS] score, left ventricular ejection fraction, systolic pulmonary artery pressure $\geq 46 \mathrm{mmHg}$, and access type), and a probability value for covariates to enter the model was set at the level of 0.10 . The results are presented as hazard ratios (HRs) adjusted for age/sex with associated $95 \% \mathrm{Cl}$. Two-sided p-values $<0.05$ were considered significant in all analyses. The SPSS 15.0 statistical package (SPSS, Inc., Chicago, IL, USA) was used to perform all statistical calculations.

\section{RESULTS}

The population consisted of 148 consecutive patients who underwent TAVI due to severe AS. One patient with
$\mathrm{BMI} \leq 18.4 \mathrm{~kg} / \mathrm{m}^{2}$ was excluded from the analysis. Of the remaining 147 patients, 37 (25.2\%) were obese, 73 were classified as overweight (49.7\%), and 37 (25.2\%) had normal weight. The median BMI was $27.0 \mathrm{~kg} / \mathrm{m}^{2}\left(24.9-30.1 \mathrm{~kg} / \mathrm{m}^{2}\right)$. Overall, obese patients were younger, with lower prevalence of incomplete coronary revascularisation (Table 1). Similar rates of comorbidities, except for previous stroke/transient ischaemic attack, were reported in all BMI categories. Mean transvalvular gradient before TAVI was highest in the overweight group (Table 1). Importantly, no differences in periprocedural risk measured with logistic EuroSCORE and the STS score were noted. Furthermore, the prevalence of lower frailty as assessed with five-metre walk test (5MWT) was observed in obese patients as compared to the overweight and normal-weight groups (Table 2). Procedural and echocardiographic data after TAVI are shown in Table 3. The median length of hospital stay was comparable between the groups (10.0 [8.0-14.0] vs. 10.0 [7.0-13.0] vs. 10.0 [8.5-11.5] days for normal-weight, overweight, and obese patients, respectively; $p=0.5$ ).

The patients were followed up for a median of 460.0 (182.0-1042.0) days. A trend towards a lower rate of in-hospital bleeding complications in overweight and obese patients was observed, with lower rates of blood transfusions in these groups as compared to normal-weight patients (Fig. 1A). No difference in antiplatelet or antithrombotic therapy on discharge was observed (Table 3). The rate of grade 3 acute kidney injury (AKI) was lowest in the overweight group (4 [10.8\%] vs. 1 [1.4\%] vs. 3 [8.1\%]; $p=0.05$ ). However, there was no difference between the groups in terms of all-cause mortality at 30 days. At 12 months, comparable rates of cerebrovascular incidents, myocardial infarction, new permanent pacemaker implantation, and new onset of atrial fibrillation were observed in all groups (Fig. 1B). The rate of 12-month all-cause mortality was lower in obese patients than in those with normal BMI and overweight (12 [32.4\%] vs. 10 [13.7\%] vs. $2[5.4 \%] ; p=0.004$; Fig. 2). Furthermore, lower mortality in this group was confirmed in patients undergoing TAVI through the femoral access (12-month all-cause mortality: $29.2 \%$ vs. $11.9 \%$ vs. $5.9 \%$; $p=0.03$ ), while no effect was reported for the transapical access ( $45.5 \%$ vs. $23.1 \%$ vs. $0.0 \%$; $p=0.35)$. A list of all variables included in the univariate analysis model for mortality is presented in Table 4 . Finally, in the Cox regression model, increase in BMI was independently associated with lower all-cause mortality ( $\mathrm{HR}[95 \% \mathrm{Cl}]$ per $1 \mathrm{~kg} / \mathrm{m}^{2}$ increase: 0.91 [0.845-0.98]; $\mathrm{p}=0.018$ ) (Table 4).

\section{DISCUSSION}

The results of our study suggest a better survival in obese and overweight patients as compared to those with normal BMI. Also, an analysis of postprocedural complications indicates a superior outcome in these patients; there was a trend towards a lower rate of in-hospital bleeding complications 
Table 1. Baseline characteristics and echocardiographic data of the patients

\begin{tabular}{|c|c|c|c|c|}
\hline \multirow[t]{2}{*}{ Variable } & \multicolumn{3}{|c|}{ Weight categories } & \multirow[t]{2}{*}{$\mathbf{p}$} \\
\hline & $\begin{array}{l}\text { Normal } \\
(n=37)\end{array}$ & $\begin{array}{l}\text { Overweight } \\
\qquad(n=73)\end{array}$ & $\begin{array}{l}\text { Obese } \\
(n=37)\end{array}$ & \\
\hline Age [years] & $83.0(78.0-85.0)$ & $83.0(79.0-86.0)$ & $78.0(77.0-82.0)$ & 0.007 \\
\hline Age $\geq 80$ years & $24(64.9)$ & $51(69.9)$ & $17(45.9)$ & 0.045 \\
\hline Male sex & $19(51.4)$ & $26(35.6)$ & $10(27.0)$ & 0.09 \\
\hline Estimated GFR [mL/min/1.73 m²] & $54.0(37.0-73.5)$ & $56.5(43.8-71.0)$ & $61.0(37.5-76.0)$ & 0.93 \\
\hline Arterial hypertension & $36(97.3)$ & $69(94.5)$ & $33(89.2)$ & 0.36 \\
\hline Diabetes mellitus & $9(24.3)$ & $26(35.6)$ & $13(35.1)$ & 0.48 \\
\hline Atrial fibrillation & $13(35.1)$ & $23(31.5)$ & $15(40.5)$ & 0.67 \\
\hline Previous MI & $11(29.7)$ & $25(34.2)$ & $12(32.4)$ & 0.92 \\
\hline Previous PCl & $11(29.7)$ & $20(27.4)$ & $12(32.4)$ & 0.87 \\
\hline Previous CABG & $4(10.8)$ & $15(20.5)$ & $8(21.6)$ & 0.43 \\
\hline COPD & $3(8.1)$ & $11(15.1)$ & $5(13.5)$ & 0.66 \\
\hline Chronic total occlusion & $4(10.8)$ & $9(12.3)$ & $1(2.7)$ & 0.27 \\
\hline Incomplete revascularisation & $10(27.0)$ & $10(13.7)$ & $2(5.4)$ & 0.030 \\
\hline Previous stroke/TIA & $8(21.6)$ & $4(5.5)$ & $5(13.5)$ & 0.037 \\
\hline Pacemaker & $6(16.2)$ & $5(6.8)$ & $6(16.2)$ & 0.18 \\
\hline Logistic EuroSCORE I [\%] & $11.6(9.7-17.8)$ & $17.0(11.4-23.0)$ & $15.0(8.0-22.0)$ & 0.08 \\
\hline STS score [\%] & $6.0(4.0-14.0)$ & $6.4(4.1-18.0)$ & $6.5(4.0-18.0)$ & 0.83 \\
\hline Maximal transvalvular gradient [mmHg] & $83.0(60.0-101.0)$ & $89.0(77.0-106.5)$ & $81.5(64.0-93.0)$ & 0.06 \\
\hline Mean transvalvular gradient [mmHg] & $48.0(34.0-60.0)$ & $53.0(44.0-66.0)$ & $48.0(40.5-53.0)$ & 0.028 \\
\hline Aortic valve area $\left[\mathrm{cm}^{2}\right]$ & $0.7(0.6-0.8)$ & $0.7(0.5-0.8)$ & $0.7(0.6-0.8)$ & 0.18 \\
\hline LVEF [\%] & $60.0(50.0-65.0)$ & $60.0(50.0-65.0)$ & $55.0(48.0-65.0)$ & 0.87 \\
\hline Aortic regurgitation: & & & & 0.16 \\
\hline None & $17(45.9)$ & $18(24.7)$ & $13(35.1)$ & \\
\hline Mild & $14(37.8)$ & $45(61.6)$ & $16(43.2)$ & \\
\hline Moderate & $5(13.5)$ & $7(9.6)$ & $7(18.9)$ & \\
\hline Severe & $1(2.7)$ & $3(4.1)$ & $1(2.7)$ & \\
\hline $\mathrm{SPAP} \geq 46 \mathrm{mmHg}$ & $16(43.2)$ & $23(31.5)$ & $14(37.8)$ & 0.48 \\
\hline
\end{tabular}

Data are presented as number (percentage) or median (interquartile range). CABG — coronary artery bypass grafting; COPD — chronic obstructive pulmonary disease; GFR — glomerular filtration rate; LVEF — left ventricular ejection fraction; $\mathrm{MI}$ - myocardial infarction; $\mathrm{PCl}$ - percutaneous coronary intervention; SPAP — systolic pulmonary artery pressure; STS — Society of Thoracic Surgeons; TIA — transient ischaemic attack

and less frequent blood transfusions in the overweight and obese. In contrast to most other studies, the rate of grade 3 AKI was lowest in the overweight group. Thus, these data may support the presence of the suggested obesity paradox in patients undergoing TAVI [3, 6, 11, 12]. However, some other studies presented contradictory results, implying no influence of BMI on the prognosis after TAVI $[13,14,18]$. Despite the similar median value of $\mathrm{BMI}$, overweight/obese groups were represented by a lower percentage of the whole population as compared with our study $[13,14,18]$. Lower periprocedural risk and rate of comorbidities in overweight/obese patients were not connected with differences in survival among BMI categories [13, 14, 18]. Furthermore, higher mortality was observed in underweight but not in overweight/obese patients as compared to the normal BMI group [18]. Low BMI was identified as an independent predictor of mortality after adjustment for covariates [18]. In contrast, a recent propensity score matching analysis cast doubt on this outcome in the TAVI population [19]. However, this study assessed the impact of BMI $<20 \mathrm{~kg} / \mathrm{m}^{2}$ defined as indicative of frailty according to VARC-2; thus, the results were not directly related to the underweight category $[17,19]$. In our study the underweight group was too small to enable the evaluation of outcomes; thus, it was excluded from the analysis.

In contrast to the above findings, a recent study presented a positive linear relationship with mortality risk reduction for 
Table 2. Frailty indices in all body mass index categories

\begin{tabular}{|c|c|c|c|c|c|}
\hline \multirow[t]{2}{*}{ Frailty evaluation tool } & \multirow[t]{2}{*}{ Frailty index } & \multicolumn{3}{|c|}{ Weight categories } & \multirow[t]{2}{*}{$\mathbf{p}$} \\
\hline & & $\begin{array}{l}\text { Normal } \\
(n=37)\end{array}$ & $\begin{array}{l}\text { Overweight } \\
\qquad(n=73)\end{array}$ & $\begin{array}{c}\text { Obese } \\
(n=37)\end{array}$ & \\
\hline 5-metre walk test [s] & $\geq 6$, frail & $10(27.0)$ & $9(12.3)$ & $2(5.4)$ & 0.020 \\
\hline \multirow[t]{3}{*}{ Elderly mobility scale [points] } & $<10$, frail & $3(8.1)$ & $3(4.1)$ & $2(5.4)$ & 0.27 \\
\hline & 10-13 & $27(73.0)$ & $45(61.6)$ & $20(54.1)$ & \\
\hline & $>13$ & $7(18.9)$ & $25(34.2)$ & $15(40.5)$ & \\
\hline \multirow[t]{4}{*}{ Canadian Study of Health and Aging scale [points] } & $1-3$ & $19(51.4)$ & $47(64.4)$ & $21(56.8)$ & 0.40 \\
\hline & 4 & $10(27.0)$ & $20(27.4)$ & $13(35.1)$ & \\
\hline & 5, frail & $2(5.4)$ & $1(1.4)$ & $0(0.0)$ & \\
\hline & $6-7$, frail & $6(16.2)$ & $5(6.8)$ & $3(8.1)$ & \\
\hline Katz index [points] & $<6$, frail & $8(21.6)$ & $7(9.6)$ & $4(10.8)$ & 0.23 \\
\hline \multirow[t]{3}{*}{ Grip strength [grade] } & Weak, frail & $3(8.1)$ & $2(2.7)$ & $2(5.4)$ & 0.47 \\
\hline & Mild & $5(13.5)$ & $5(6.8)$ & $4(10.8)$ & \\
\hline & Strong & $29(78.4)$ & $66(90.4)$ & $31(83.8)$ & \\
\hline Identification of Seniors at Risk scale [points] & $\begin{array}{c}\geq 2 \text {, functional } \\
\text { decline, frail }\end{array}$ & $14(37.8)$ & $27(37.0)$ & $12(32.4)$ & 0.90 \\
\hline
\end{tabular}

Data are presented as number (percentage).

Table 3. Procedural and echocardiographic data, and treatment after the procedure

\begin{tabular}{|c|c|c|c|c|}
\hline \multirow[t]{2}{*}{ Variable } & \multicolumn{3}{|c|}{ Weight categories } & \multirow[t]{2}{*}{ p } \\
\hline & $\begin{array}{l}\text { Normal } \\
(n=37)\end{array}$ & $\begin{array}{l}\text { Overweight } \\
\qquad(n=73)\end{array}$ & $\begin{array}{c}\text { Obese } \\
(n=37)\end{array}$ & \\
\hline Access type: & & & & 0.047 \\
\hline Transfemoral & $24(64.9)$ & $59(80.8)$ & $34(91.9)$ & \\
\hline Transapical & $11(29.7)$ & $13(17.8)$ & $3(8.1)$ & \\
\hline Transaortic & $1(2.7)$ & $1(1.4)$ & $0(0.0)$ & \\
\hline Subclavian & $1(2.7)$ & $0(0.0)$ & $0(0.0)$ & \\
\hline Maximal transvalvular gradient $[\mathrm{mmHg}]$ & $12.8(10.1-19.0)$ & $14.0(10.0-18.0)$ & $15.0(10.0-19.5)$ & 0.84 \\
\hline Median transvalvular gradient $[\mathrm{mmHg}]$ & $7.0(6.0-11.0)$ & $7.4(5.0-10.0)$ & $8.0(6.0-10.5)$ & 0.88 \\
\hline LVEF [\%] & $48.5(40.0-55.0)$ & $48.0(44.0-57.5)$ & $50.0(42.0-55.0)$ & 0.90 \\
\hline Paravalvular leak: & & & & 0.84 \\
\hline None & $21(56.8)$ & $41(56.2)$ & $21(56.8)$ & \\
\hline Mild & $13(35.1)$ & $28(38.4)$ & $14(37.8)$ & \\
\hline Moderate & $3(8.1)$ & $2(2.7)$ & $2(5.4)$ & \\
\hline Severe & $0(0.0)$ & $2(2.7)$ & $0(0.0)$ & \\
\hline $\begin{array}{l}\text { Antiplatelet and antithrombotic therapy } \\
\text { on discharge after the procedure: }\end{array}$ & & & & 0.9 \\
\hline Triple antithrombotic therapy & $10(27.0)$ & $13(17.8)$ & $8(21.6)$ & \\
\hline Dual antiplatelet therapy & $16(43.2)$ & $35(47.9)$ & $16(43.2)$ & \\
\hline ASA alone & $8(21.6)$ & $16(21.9)$ & 7 (18.9) & \\
\hline Oral anticoagulant with ASA & $3(8.1)$ & $9(12.3)$ & $6(16.2)$ & \\
\hline
\end{tabular}

Data are presented as number (percentage) or median (interquartile range). ASA — acetylsalicylic acid; LVEF — left ventricular ejection fraction 


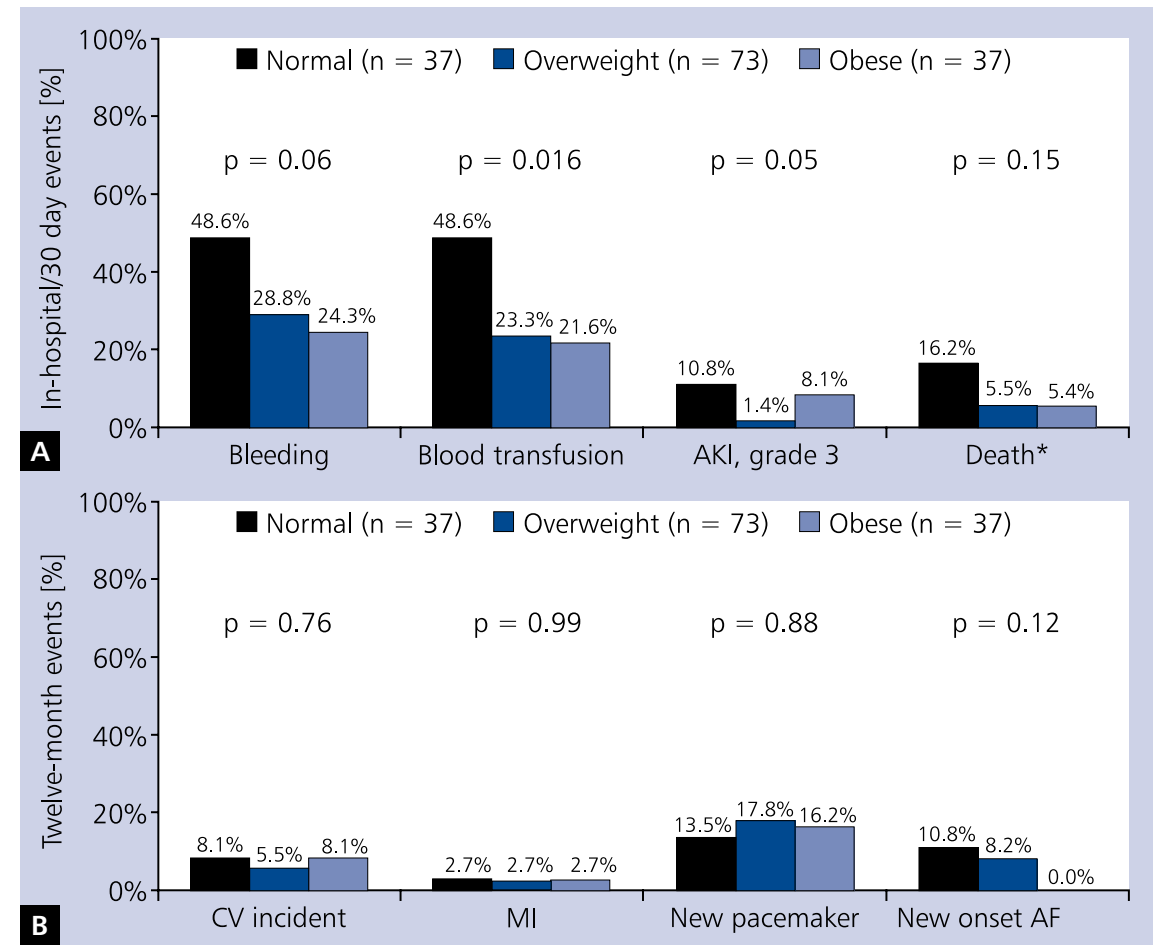

Figure 1. In-hospital/30-day (A) and 12-month (B) outcomes after transcatheter valve implantation stratified by body mass index categories; $\mathrm{AF}$ - atrial fibrillation; $\mathrm{AKI}$ - acute kidney injury; $\mathrm{CV}$ - cerebrovascular; $\mathrm{MI}$ - myocardial infarction; *30-day mortality

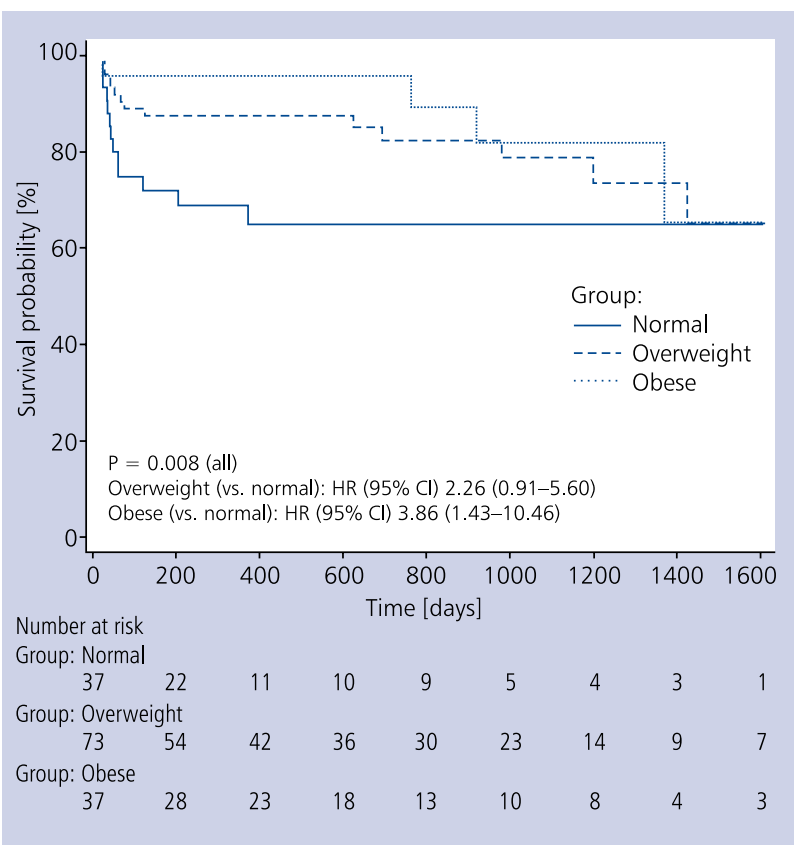

Figure 2. Kaplan-Meier curves for survival after transcatheter valve implantation stratified by body mass index categories; $\mathrm{Cl}$ - confidence interval; $\mathrm{HR}$ - hazard ratio every increase of one unit of BMI [6]. Other studies reported better survival among the overweight/obese patients in both 30-day and 12-month observation [6, 11]. However, some analyses presenting a beneficial outcome in the obese/overweight groups included a smaller percentage of patients with $\mathrm{BMI} \geq 25 \mathrm{~kg} / \mathrm{m}^{2}$ in comparison with our study [3, 11]. Finally, a recent large meta-analysis presented similar rates of 30-day and long-term all-cause mortality in overweight as compared with normal-weight patients [20]. Likewise, no differences in 30-day survival and procedural complications were observed between the obese and normal BMI categories [20]. However, lower mortality among the obese in long-term follow-up was confirmed (HR 0.79; 95\% Cl 0.67-0.93; p = 0.004) [20]. Another meta-analysis presented an association between obesity/overweight and favourable outcome in TAVI patients for both continuous and categorised BMI values [21]. Interestingly, a different study postulated that weight change before TAVI is a more relevant marker of outcome than absolute weight at the time of the procedure [22]. Furthermore, BMI category was not correlated with mortality in patients with stable weight at the time of TAVI [22]. Body weight change was not captured in our study. 
Table 4. Univariate and multivariate analysis models for mortality

\begin{tabular}{lcc|} 
Variable & HR & $95 \%$ CI \\
\hline Univariate analysis: & & \\
$\quad$ Age & 1.024 & $0.973-1.079$ \\
Male sex & 2.452 & $1.212-4.959$ \\
BMI & 0.923 & $0.851-1.001$ \\
eGFR & 0.972 & $0.954-0.991$ \\
Arterial hypertension & 0.915 & $0.218-3.847$ \\
Diabetes mellitus & 1.443 & $0.710-2.931$ \\
Atrial fibrillation & 0.916 & $0.431-1.948$ \\
Previous MI & 1.500 & $0.730-3.081$ \\
Previous PCI & 1.974 & $0.977-3.989$ \\
Previous CABG & 0.288 & $0.068-1.218$ \\
COPD & 2.436 & $1.111-5.341$ \\
Incomplete revascularisation & 7.607 & $3.727-15.527$ \\
Previous stroke/TIA & 3.966 & $1.789-8.795$ \\
Pacemaker implantation & 0.878 & $0.266-2.896$ \\
Logistic EuroSCORE I & 1.020 & $0.981-1.061$ \\
STS score & 0.993 & $0.953-1.035$ \\
LVEF & 1.002 & $0.972-1.032$ \\
SPAP $\geq 46$ mmHg & 1.537 & $0.749-3.154$ \\
Access type (femoral vs. other) & 0.783 & $0.349-1.758$ \\
Multivariate analysis & & \\
BMI & 0.91 & $0.845-0.98$ \\
Incomplete revascularisation & 5.322 & $2.389-11.853$ \\
eGFR & 0.961 & $0.94-0.984$ \\
Previous stroke/TIA & 3.988 & $1.644-9.674$ \\
\hline
\end{tabular}

$\mathrm{BMI}$ - body mass index; $\mathrm{Cl}$ - confidence interval; eGFR - estimated glomerular filtration rate; HR - hazard ratio; other abbreviation — see Table 1

The inconsistencies regarding the obesity paradox in TAVI populations might be related to differences in the categorisation of BMI as a variable (continuous or categorical) and different definitions of obesity. The protective effects of obesity/overweight in our study might be partially linked to the coexisting differences in age and comorbidities between the groups. These observations seem to be more important in combination with the independent predictors of mortality identified in our study. Intuitively, obesity might lead to higher prevalence of access-site and bleeding complications as well as blood transfusion, but this association was not established in our study. Most of the studies confirmed no differences in $\mathrm{AKI}$ and bleeding or vascular complication incidence between BMl categories [3, 14, 20, 23]. A trend towards worse renal function and more periprocedural complications in obese patients was reported by De Palma et al. [22]; however, the percentage of obese patients in their study was relatively small. Furthermore, obesity was associated with higher incidence of vascular complications and bleeding, whereas blood transfusions were more common in the normal-weight group [6]. The obese patients had a higher prevalence of comorbidities, including diabetes mellitus [6]. A link between major vascular and bleeding complications and insulin-treated diabetes was reported [24, 25]. Improved operator skills and a reduction in sheath and valve sizes may be partially responsible for the decreased rate of vascular complications as compared to previous studies. Several reports demonstrated a link between blood transfusion and mortality following TAVI [26, 27]. In our study, a higher prevalence of $\mathrm{AKI}$ in patients defined as normal-weight was observed. A recent study proved that bleeding complications and blood transfusion were predictors of AKI [27]. In addition, the detrimental effect of red blood cell transfusion on $\mathrm{AKI}$ and long-term survival was associated with an increased number of transfusions [28].

Despite all the above factors affecting the outcome, the mechanism behind the obesity paradox in the TAVI population is still unclear. Some might argue that the obese group consisted of younger patients with potentially lower procedural risk and hence the outcomes have been biased. Younger patients might seek medical care earlier, thus a more aggressive treatment with cardioprotective drugs could lead to a beneficial outcome of interventional treatment $[5,15]$. However, in our study increased BMI was identified as an independent predictor of improved survival even after adjusting for age and sex. Several studies have also shown that the population with increased $\mathrm{BMI}$ received more optimal medical treatment compared with those with a normal BMI [15]. Investigators denying the obesity paradox postulated an incremental role of metabolic reserve in resistance of detrimental effects of acute morbidities or procedural stress [3, 5, 15]. Another possible protective mechanism relies on higher level of tumour necrosis factor alpha (TNF- $\alpha$ ) receptor produced by excessive adipose tissue $[3,5,15,29]$. Thus, the adverse effect of increasing TNF- $\alpha$ in patients with chronic inflammation diseases is neutralised [29]. Likewise, an enhanced level of circulating lipoproteins may counteract lipopolysaccharides stimulating the production of inflammatory cytokines [5, 15]. A possible explanation for the discrepancy in survival might be also connected with frailty indices. In our study, obese and overweight patients had a lower rate of frailty measured with 5MWT as compared to normal BMI patients. It could be a potential marker of better mobility and general health status in this group. The evaluation of frailty as well as quality of life [30] have been presented as important factors of overall health status in TAVI patients [10, 31]. However, BMI does not enable the discrimination between the components of body or the type and location of fat tissue. To avoid potential limits of BMI, frailty should be evaluated to anticipate the potential futility of TAVI. Currently, BMI is not incorporated in commonly used 
risk scores aimed at predicting mortality after TAVI. However, the available data may suggest the inclusion of this measure in new TAVI-oriented risk score models.

The study has all the limitations of a single-centre registry. The observational nature of this study could not provide clear evidence of an association between increased BMI and survival benefit, and causality could not be established. BMI was used only to categorise patients into the obese/overweight group. However, a combination of BMI with central obesity assessment (waist-to-hip ratio, triceps skinfold thickness, or waist circumference) could be more valuable in the evaluation of survival benefit after TAVI [3]. Because the change in body weight during follow-up was not captured, the potential impact of body mass change on outcomes cannot be excluded. Importantly, weight was measured after the onset of the disease with potential concomitant fluid retention. Thus, it may have not represented the true "dry weight" of the body and may have overestimated BMI with erroneous categorisation to the obese or overweight group.

In conclusion, increased BMI was independently associated with survival benefit after TAVI. Therefore, our results may support the presence of so-called obesity paradox in the TAVI population.

\section{Conflict of interest: none declared}

\section{References}

1. Poirier P, Giles TD, Bray GA, et al. Obesity and cardiovascular disease: pathophysiology, evaluation, and effect of weight loss: an update of the 1997 American Heart Association Scientific Statement on Obesity and Heart Disease from the Obesity Committee of the Council on Nutrition, Physical Activity, and Metabolism. Circulation. 2006; 113(6): 898-918, doi: 10.1161/CIRCULATIONAHA.106.171016, indexed in Pubmed: 16380542.

2. Oga EA, Eseyin OR. The obesity paradox and heart failure: a systematic review of a decade of evidence. J Obes. 2016; 2016: 9040248, doi: 10.1155/2016/9040248, indexed in Pubmed: 26904277.

3. Abawi M, Rozemeijer R, Agostoni P, et al. Effect of body mass index on clinical outcome and all-cause mortality in patients undergoing transcatheter aortic valve implantation. Neth Heart J. 2017; 25(9): 498-509, doi: 10.1007/s12471-017-1003-2, indexed in Pubmed: 28536936

4. Galyfos G, Geropapas GI, Kerasidis S, et al. The effect of body mass index on major outcomes after vascular surgery. J Vasc Surg. 2017; 65(4): 1193-1207, doi: 10.1016/j.jvs.2016.09.032, indexed in Pubmed: 27876519.

5. Bundhun PK, Li N, Chen MH. Does an obesity paradox really exist after cardiovascular intervention?: a systematic review and meta-analysis of randomized controlled trials and observational studies. Medicine (Baltimore). 2015; 94(44): e1910, doi: 10.1097/MD.0000000000001910, indexed in Pubmed: 26554791.

6. Konigstein M, Havakuk O, Arbel Y, et al. The obesity paradox in patients undergoing transcatheter aortic valve implantation. Clin Cardiol. 2015; 38(2): 76-81, doi: 10.1002/clc.22355, indexed in Pubmed: 25649013

7. Leon MB, Smith CR, Mack M, et al. Transcatheter aortic-valve implantation for aortic stenosis in patients who cannot undergo surgery. N Engl J Med. 2010; 363(17): 1597-1607, doi: 10.1056/NEJMoa1008232, indexed in Pubmed: 20961243.
8. Tokarek T, Sobczyński R, Dziewierz A, et al. Clinical outcomes in patients after surgical and transcatheter aortic valve replacement. Pol Arch Med Wewn. 2015; 125(10): 755-764, indexed in Pubmed: 26397310.

9. Olszewska K, Tokarek T, Bętkowska-Korpała B, et al. Assessment of cognitive functions and quality of life in patients scheduled for transcatheter aortic valve implantation: a pilot study. Adv Interv Cardiol. 2017; 13(3): 258-262, doi: 10.5114/aic.2017.70199, indexed in Pubmed: 29056999.

10. Kleczynski P, Dziewierz A, Bagienski M, et al. Impact of frailty on mortality after transcatheter aortic valve implantation. Am Heart J. 2017; 185: 52-58, doi: 10.1016/j.ahj.2016.12.005.

11. Yamamoto M, Mouillet G, Oguri A, et al. Effect of body mass index on 30- and 365-day complication and survival rates of transcatheter aortic valve implantation (from the FRench Aortic National CoreValve and Edwards 2 [FRANCE 2] registry). Am J Cardiol. 2013; 112(12): 1932-1937, doi: 10.1016/j.amjcard.2013.08.022, indexed in Pubmed: 24063832.

12. González-Ferreiro R, Muñoz-García AJ, López-Otero D, et al. Prognostic value of body mass index in transcatheter aortic valve implantation: A. Int J Cardiol. 2017; 232: 342-347, doi: 10.1016/j. ijcard.2016.12.051, indexed in Pubmed: 28089155.

13. van der Boon RMA, Chieffo A, Dumonteil N, et al. Effect of body mass index on short- and long-term outcomes after transcatheter aortic valve implantation. Am J Cardiol. 2013; 111(2): 231-236, doi: 10.1016/j.amjcard.2012.09.022, indexed in Pubmed: 23102879 .

14. Abramowitz Y, Chakravarty T, Jilaihawi H, et al. Impact of body mass index on the outcomes following transcatheter aortic valve implantation. Catheter Cardiovasc Interv. 2016; 88(1): 127-134, doi: 10.1002/ccd.26394, indexed in Pubmed: 26756702.

15. Goel K, Lopez-Jimenez F, De Schutter A, et al. Obesity paradox in different populations: evidence and controversies. Future Cardiol. 2014; 10(1): 81-91, doi: 10.2217/fca.13.84, indexed in Pubmed: 24344665.

16. Executive summary of the clinical guidelines on the identification, evaluation, and treatment of overweight and obesity in adults. Arch Intern Med. 1998; 158(17): 1855-1867, indexed in Pubmed: 9759681.

17. Kappetein AP, Head SJ, Généreux P, et al. Updated standardized endpoint definitions for transcatheter aortic valve implantation: the Valve Academic Research Consortium-2 consensus document. EuroIntervention. 2012; 8(7): 782-795, doi: 10.4244/EIJV8I7A121, indexed in Pubmed: 23022744.

18. Koifman E, Kiramijyan S, Negi SI, et al. Body mass index association with survival in severe aortic stenosis patients undergoing transcatheter aortic valve replacement. Catheter Cardiovasc Interv. 2016; 88(1): 118-124, doi: 10.1002/ccd.26377, indexed in Pubmed: 26715505.

19. Yamamoto M, Hayashida K, Watanabe $\mathrm{Y}$, et al. Effect of body mass index $<20 \mathrm{~kg} / \mathrm{m}(2)$ on events in patients who underwent transcatheter aortic valve replacement. Am J Cardiol. 2015; 115(2): 227-233, doi: 10.1016/j.amjcard.2014.10.026, indexed in Pubmed: 25534764.

20. Sannino A, Schiattarella GG, Toscano E, et al. Meta-analysis of effect of body mass index on outcomes after transcatheter aortic valve implantation. Am J Cardiol. 2017; 119(2): 308-316, doi: 10.1016/j. amjcard.2016.09.031, indexed in Pubmed: 27839771.

21. Takagi H, Umemoto T. J Cardiovasc Surg (Torino). 2017; 58(1): 113-120, doi: 10.23736/S0021-9509.16.09233-8, indexed in Pubmed: 26939045.

22. De Palma R, Ivarsson J, Feldt K, et al. The obesity paradox: An analysis of pre-procedure weight trajectory on survival outcomes in patients undergoing transcatheter aortic valve implantation. Obes Res Clin Pract. 2018; 12(1): 51-60, doi: 10.1016/j. orcp.2017.05.006, indexed in Pubmed: 28668555. 
23. Arsalan M, Filardo G, Kim WK, et al. Prognostic value of body mass index and body surface area on clinical outcomes after transcatheter aortic valve implantation. Clin Res Cardiol. 2016; 105(12): 1042-1048, doi: 10.1007/s00392-016-1027-4, indexed in Pubmed: 27535139.

24. Généreux P, Webb JG, Svensson LG, et al. Vascular complications after transcatheter aortic valve replacement: insights from the PARTNER (Placement of AoRTic TraNscathetER Valve) trial. J Am Coll Cardiol. 2012; 60(12): 1043-1052, doi: 10.1016/j. jacc.2012.07.003, indexed in Pubmed: 22883632.

25. Tokarek T, Dziewierz A, Wiktorowicz A, et al. Effect of diabetes mellitus on clinical outcomes and quality of life after transcatheter aortic valve implantation for severe aortic valve stenosis. Hellenic J Cardiol. 2018; 59(2): 100-107, doi: 10.1016/j. hjc.2017.08.002, indexed in Pubmed: 28807801.

26. Nuis RJ, Van Mi, Tzikas A, et al. Frequency, determinants, and prognostic effects of acute kidney injury and red blood cell transfusion in patients undergoing transcatheter aortic valve implantation. Catheter Cardiovasc Interv. 2011; 77: 881-889.

27. Tchetche D, Van der Boon RMA, Dumonteil N, et al. Adverse impact of bleeding and transfusion on the outcome post-transcatheter aortic valve implantation: insights from the Pooled-RotterdAm-Milano-Toulouse In Collaboration Plus (PRAGMATIC
Plus) initiative. Am Heart J. 2012; 164(3): 402-409, doi: 10.1016/j. ahj.2012.07.003, indexed in Pubmed: 22980308.

28. Liao YB, Deng XX, Meng Y, et al. Predictors and outcome of acute kidney injury after transcatheter aortic valve implantation: a systematic review and meta-analysis. EuroIntervention. 2017; 12(17): 2067-2074, doi: 10.4244/EIJ-D-15-00254, indexed in Pubmed: 27890858.

29. Mohamed-Ali V, Goodrick S, Bulmer K, et al. Production of soluble tumor necrosis factor receptors by human subcutaneous adipose tissue in vivo. Am J Physiol. 1999; 277(6): E971-E975, doi: 10.1152/ajpendo.1999.277.6.E971, indexed in Pubmed: 10600783.

30. Stańska A, Jagielak D, Brzeziński M, et al. Improvement of quality of life following transcatheter aortic valve implantation in the elderly: a multi-centre study based on the Polish national TAVI registry. Kardiol Pol. 2017; 75(1): 13-20, doi: 10.5603/KP.a2016.0164, indexed in Pubmed: 27878802.

31. Bagienski M, Tokarek T, Wiktorowicz A, et al. Sex-related differences in clinical outcomes and quality of life after transcatheter aortic valve implantation for severe aortic stenosis. Adv Interv Cardiol. 2017; 13(3): 233-239, doi: 10.5114/aic.2017.70195, indexed in Pubmed: 29056996.

Cite this article as: Tokarek TA, Dziewierz A, Sorysz D, et al. The obesity paradox in patients undergoing transcatheter aortic valve implantation: is there any effect of body mass index on survival? Kardiol Pol. 2019; 77(2): 190-197, doi: 10.5603/KP.a2018.0243.

\section{WHAT IS NEW?}

We demonstrated that 12-month all-cause mortality after transcatheter aortic valve implantation was lower in obese patients as compared to normal-weight and overweight groups. However, there was no difference in 30-day survival between body mass index categories. Increase in body mass index was independently associated with lower all-cause mortality after this procedure. A trend towards a lower rate of in-hospital bleeding complications and less frequent blood transfusions in overweight and obese patients was observed. The rate of grade 3 acute kidney injury was lowest in the overweight group. Body mass index is not incorporated in commonly used risk scores to predict mortality after transcatheter aortic valve implantation. However, the available data supporting the presence of the so-called obesity paradox may suggest inclusion of this measure in new risk score models oriented towards transcatheter aortic valve implantation. 